\title{
The influence of Mat Pilates associated with perineal contraction in the female sexual response
}

\author{
Maria Eunice Chagas Oliveira', Fernanda Gonçalves de Oliveira', Nazete dos Santos Araújo², Erica Feio Carneiro Nunes³, \\ Cibele Nazaré Câmara Rodrigues ${ }^{1}$
}

\begin{abstract}
Background: The Pilates Method is a program of physical and mental training that involves the whole body, aiming at the gain of muscular strength, mainly of the central region, formed by the abdominal muscles, the spine and the pelvic floor muscles (PFM). The PFM responds to sexual stimulation, with increased local blood circulation and involuntary contractions during orgasm. The training of this musculature assists in the female sexual function. Objective: To evaluate the influence of Pilates Mat associated with perineal contraction in the female sexual response. Method: Uncontrolled clinical trial in which participated twelve women between 20 and 50 years old, who performed Mat Pilates classes associated with perineal exercises, three times a week. The sexual response was evaluated through the Female Sexual Function Index (FSFI) and the contraction capacity of PFM through the Functional Evaluation of the Pelvic Floor (FEPF) before and after 21 sessions. Results: Given the proposed treatment, the FSFI responded positively (0.0099), with an improvement in the median and interquartile range that initially was $25.6 \pm 5.4$ and increased to $28.4 \pm 1.2$. The Functional Evaluation of the Pelvic Floor (FEPF) also achieved significant improvement $(p=0.0077)$, increased from the initial median and interquartile range of $2 \pm 1.5$ to $4 \pm 1$. Conclusion: Mat Pilates provides encouraging results, and its use is relevant to promote improved sexual response and strength gain of the pelvic floor muscle.
\end{abstract}

Keywords: Pilates Method, Pelvic Floor, Sexuality.

\section{INTRODUCTION}

Most women have difficulty in contracting their perineal muscles and it is up to the physiotherapist to assist the proprioception in this region ${ }^{(1)}$. Through the practice of specific exercises for the pelvic floor can be acquired its muscular strength, based on the precept that the repeated voluntary movements provide beneficial effects as development, improvement, restoration or maintenance of strength, endurance, mobility, flexibility, relaxation, coordination, improvement of the pain, as well as enabling a satisfactory sexual life ${ }^{(2)}$.

Joseph Humbertus Pilates, was born in Germany in 1880. He was a sick child suffering from asthma, rickets and rheumatic fever. Because of these factors, he sought to become physically stronger by studying several different forms of movement during his lifetime ${ }^{(3)}$. Then it was developed the original Pilates from which derives the Mat Pilates, a method performed on the ground with a therapeutic ball (Swiss ball) or other devices and present different degrees of difficulty of the exercises. This practice aims to correct muscular imbalances, postural improvement, flexibility, body awareness and fitness.
In addition, when practiced regularly and correctly, the Pilates method can promote physical and emotional benefits ${ }^{(4,5)}$.

The Pilates method is also known as Contrology or Art of Control, which refers to the ability of the human being to move with knowledge and mastery and must present coordination between body, mind and spirit ${ }^{(6)}$. Pilates is based on six basic principles, present in the exercises: centering, concentration, control, precision, flow and breathing ${ }^{(7)}$.

Centering, also known as core, power house or engagement, corresponds to the specific muscle groups such as the anterior abdominal region and especially the transverse muscle, which is responsible for the increase of the intra-abdominal pressure and loin-pelvic stability, besides being synergist of the PFM, spine extensors, hip extensors, hip flexors, and pelvic floor muscle $^{(8)}$. The activation of the Power house consists of an isotonic contraction (concentric and eccentric) of the lower abdominal muscles added to the co-activation of the pelvic floor, applying from 20 to $30 \%$ of voluntary contraction of the involved muscles and causing an increase in intra-abdominal pressure $^{(9)}$. 
The fact that most Pilates exercises are performed in conjunction with the recruitment of the pelvic floor muscle fibers, most Pilates instructors believe that this method may have a significant effect on the increase in strength or contractility of this muscle. Since the Pilates method improves the function of PFM, it could be a possibility for the treatment and prevention of pelvic floor dysfunction ${ }^{(10)}$.

The pelvic floor muscle (PFM) constricts to maintain urinary and fecal continence and relaxes allowing intestinal and bladder emptying, prevents displacement of the pelvic organs and participates in the normal female sexual response ${ }^{(11,12)}$. Therefore, PFM can interfere both positively and negatively in the female sexual function ${ }^{(13)}$.

During orgasm, PFM reacts to sexual stimuli with increased local blood circulation and involuntary contractions ${ }^{(14)}$. Sexual satisfaction results from a sufficiently long stimulation, and the feeling of sexual arousal should lead to orgasm, being free of negative results, such as pain. Sexual dissatisfaction may be the result of sexual dysfunction, or may exist independently of such dysfunctions ${ }^{(15)}$. Dyspareunia is an important sexual dysfunction that causes great damage to the quality of life of women and can be commonly found in clinical practice ${ }^{(16)}$.

Many instructors believe that the Pilates method can produce significant improvements in pelvic floor strength due to the fact that most exercises are performed with contractions of $\mathrm{it}^{(17)}$.

Considering the above, this study was developed with the objective of evaluating the influence of the Pilates method associated with perineal contraction in the female sexual response.

\section{METHOD}

This study is an uncontrolled clinical trial, approved by the Ethics Committee of the "Núcleo de Medicina Tropical" (NMT) of the Federal University of Pará (CAAE: 72657917.5.0000.5172; number: 2.456.091) which was developed in compliance with Resolution 466/2012 of the National Health Council.

The research was carried out in the physiotherapy clinic CAFISIO MULHER, specialized in female care, located in the city of Belém do Pará, from October to November 2017. The target group was women who met the following eligibility criteria: heterosexual women, aged between 20 and 50 years old, who had been sexually active for more than two years. The exclusion criteria were: pregnant women; with physical and/or mental disabilities; practitioner of physical activity of high performance; who had undergone recent pelvic and/or abdominal surgery.

The selection of volunteers was convenience sampling, through an invitation in social networks and pamphlets distributed in physiotherapy clinics, and they accepted to participate in the research through the signing of the Informed Consent Form.
Initially, the sample consisted of 15 women, however, during the study, 3 participants gave up, finishing with 12 participants.

\section{Procedures}

Initially, each participant underwent a physiotherapeutic evaluation containing anamnesis and physical examination. In the anamnesis was approached the number of gestations, type of birth, presence or absence of lacerations and/or episiotomy, urinary symptoms, and associated diseases. Then it was applied the Female Sexual Function Index (FSFI), created and validated by Rosen et al. $200{ }^{(18)}$. Composed of 19 items that evaluate female sexual functioning in six domains: desire, arousal, lubrication, orgasm, satisfaction and pain.

In the physical examination the procedures were performed for the Functional Evaluation of the Pelvic Floor (FEPF) through bidigital palpation, in which the examiner, with hand gloved and greased in gel, inserted the index and middle fingers into the vaginal canal. The participant was instructed to contract musculature around the examiner's fingers three times, similar to the action of "holding the pee": the first contraction was the character of recognition to the given command; in the second one the patient was asked to contract as much as possible and this was valid for analysis, considering the degrees according to the Modified Oxford Grading Scale $\mathrm{e}^{(19)}$; and the third was to sustain the contraction for as long as it could.

Subsequently, each participant underwent a proprioceptive training of the perineal contraction in order to raise awareness of the PFM contraction during the Pilates Mat that would be proposed. Proprioception was performed through the Biofeedback instrument of Phenix, USB-4 model (VIVALTS, Paris, France), viewing only the physiological frequencies (between 10 and $1000 \mathrm{~Hz}$ ), and the other frequencies are eliminated by analogue and digital filtering. A vaginal probe $5 \mathrm{~cm}$ long and $5.5 \mathrm{~cm}$ in diameter was used, containing two metal rings of $1 \mathrm{~cm}$ each and $3 \mathrm{~cm}$ apart from each other, with a lubricating vaginal gel and inserted at a distance of $3 \mathrm{~cm}$ from the posterior commissure of the vulva. The proprioceptive training was performed with the patient in a modified gynecological position (flexo-abduction of the hip, with the feet resting on the stretcher). The participant was asked to perform a quick contraction to verify the proprioception of the contraction commands already established, which could be visualized through the computer monitor.

The Pilates protocol (Table 1) was performed with 50-minute sessions, 3 times a week for 7 weeks, totaling 21 sessions. The progression of the exercises was based on the increase in the number of repetitions of the exercise and in the positions variations from beginner to intermediate and advanced, for each exercise. The movements were repeated eight to ten times each, with rest of 40-50s or in specific exercises contraction was requested in isometry. During the 
Table 1. Protocol of exercises applied to the participants. Belém/PA, 2018

\begin{tabular}{|c|c|}
\hline $\begin{array}{l}\text { Exercises } \\
\text { (Sessions 1-21) }\end{array}$ & Description \\
\hline Pilates Breathing & Breath in slowly and focus on the movement of the diaphragm. When exhaling the air, perform isometry of the power house. \\
\hline Shoulder Bridge & $\begin{array}{l}\text { Lying in dorsal decubitus, flexed legs and parallel feet. The movement is initiated by the activation of the power house, followed by } \\
\text { gluteal contraction, retroversion and elevation of the pelvis. The return is segmented to the starting position. }\end{array}$ \\
\hline Swimming & $\begin{array}{l}\text { Lying in ventral decubitus, LL extended and UL flexed at } 180 \text {. Breath in to extend the trunk and during expiration lumbar and } \\
\text { pelvis become neutral and the upper portion of the spine and hip are extended. Arms and legs raised out of the ground alternately } \\
\text { and quickly. The cycle is carried out in inspiration, by } 5 \text { counts. }\end{array}$ \\
\hline Single Leg Stretch & $\begin{array}{l}\text { Lying in the supine position raise the shoulders and keep the chin toward the chest, raise one leg and hold the ankle, return to the } \\
\text { starting position and alternate legs. }\end{array}$ \\
\hline The Hundred & $\begin{array}{l}\text { Lying in dorsal decubitus, knees flexed, feet resting on the ground, arms along the body. Breath in and raise the head and trunk } \\
\text { until reaching the base of the shoulder blades. The arms stretch forward as if they going to reach the feet. Move your arms up and } \\
\text { down with quick and short movements. Breath in for } 5 \text { pulses and cycle until } 100 \text { pulses are completed. }\end{array}$ \\
\hline $\begin{array}{l}\text { The Hundred } \\
\text { (adapted) }\end{array}$ & The same sequence described above is performed, but with the legs extended without touching the ground. \\
\hline The Cat & $\begin{array}{l}\text { Four prone supports on the floor. Align hands/elbows to hips. Legs to the width of the hips. Breath in to initiate and perform trunk } \\
\text { flexion along with expiration and then performs inspiratory trunk extension. }\end{array}$ \\
\hline Free Squatting & Standing, with a Swiss ball in hand, a free squat is performed at $90 \circ$ associated with UL flexion at $180^{\circ}$. \\
\hline Afundo & On foot and hands resting on the bar, alternating legs to front and behind while performing squatting. \\
\hline $\begin{array}{l}\text { Abdominal with } \\
\text { Swiss ball }\end{array}$ & With the prone body and the front of the legs resting on the ball, are performed hip flexion and extension. \\
\hline Scissors (adapted) & $\begin{array}{l}\text { In dorsal decubitus, the trunk flexion to the base of the scapula and hip flexion is performed, alternating the legs like "scissors" and } \\
\text { passing a medium ball between the legs during the movement. }\end{array}$ \\
\hline $\begin{array}{l}\text { Shoulder Bridge } \\
\text { (Unilateral) }\end{array}$ & $\begin{array}{l}\text { Lying in dorsal decubitus, one leg flexed and one extended in the direction of the knee. The movement is initiated by the activation } \\
\text { of the power house, followed by gluteal contraction, retroversion and elevation of the pelvis. The return is segmented to the } \\
\text { starting position. }\end{array}$ \\
\hline Plank & $\begin{array}{l}\text { With the body in pronation, elbows supported in the ground, extended body and tip of the feet on the ground, it is performed } \\
\text { support of the body in isometry, with neutral pelvis, scapula and column, far from the ground. }\end{array}$ \\
\hline The Leg Pull Front & $\begin{array}{l}\text { With the body in pronation, arms extended and hands supported on the ground, body extended in unipodal support on the } \\
\text { ground, is carried out support of the body in isometry, with neutral pelvis, scapula and column, far from the ground. }\end{array}$ \\
\hline The Side Bend & $\begin{array}{l}\text { On a side board, breath in to prepare the movement. During expiration a lateral plank and elevation of the free arm is performed, } \\
\text { making a parabola on the body, raised hip forming an arch with the body. }\end{array}$ \\
\hline The side Kick & $\begin{array}{l}\text { In lateral decubitus with hands at the nape of the neck with abducted arms and one arm resting on the ground. Breath in lifting } \\
\text { the legs of the ground for axial stretching. The legs change like "scissors" in the air. }\end{array}$ \\
\hline Swan & $\begin{array}{l}\text { In ventral decubitus with extended legs and arms at } 180^{\circ} \text { of shoulder flexion. Breath in to start and when breathing out the head, } \\
\text { arms and legs are raised and maintains only abdomen and hip on the ground in isometry. }\end{array}$ \\
\hline The Push Up & $\begin{array}{l}\text { In plank posture, with hands on the ground, breath in to start. During the expiration the support movement is performed in } \\
\text { parallel with the ground, but without touching it. Breath in to prepare and breath out "walking" with your hands until you touch } \\
\text { your ankles and stay in the orthostatic position. }\end{array}$ \\
\hline The Side to Side & $\begin{array}{l}\text { In dorsal decubitus, arms extended and slightly abducted along the body and extended LL with } 90 \circ \text { of hip flexion. Breath in to start } \\
\text { movement and during exhalation the two legs are raised laterally. }\end{array}$ \\
\hline
\end{tabular}

exercises, the contraction of the pelvic floor muscle was requested at the time of expiration.

During the intervention period, Mat Pilates classes were applied by the same instructor duly qualified for this role. It is emphasized that the initial evaluation, before the intervention, and the final evaluation, after the 21 sessions, were performed by the same examiner following the variables of FEPF and total score of FSFI.

The collected data was stored in a database in the Microsoft Excel 2010 program, in which each subject was registered under the initials of their name. The non-parametric Wilcoxon test was used to compare the median of the initial and final scores of the sexual function questionnaire and the pelvic floor contraction capacity. Due to the non-parametric character of these data, results were initially detailed at median \pm interquartile range. Statistical analysis and Figures were performed in Figure Pad 5.0 software and the $95 \%$ confidence interval was used, and $p$ values of less than 0.05 were considered significant.

\section{RESULTS}

Twelve women participated in this study, with a mean age of $35 \pm 5.18$ years. They declared themselves to not be smokers, hypertensive and/or diabetic. Of the participants who 
performed vaginal birth, none had laceration. According to the general aspects of the participants (Table 2), it is noted that $50 \%$ of the sample are married, and $75 \%$ of them had one and/or two pregnancies; of the participants who had gestations, $66.66 \%$ were the cesarean type and $33.33 \%$ were the vaginal type, among the vaginal deliveries occurred episiotomy in $66.66 \%$; and $41.67 \%$ of the sample population characterized at least one type of urinary incontinence (UI) symptom (burning, dripping, urgency, post-urination desire, loss of effort).

According to the initial and final comparison of FEPF as the modified Oxford Grading Scale (Figure 1), is possible to analyzed that there was a significant improvement $(0.0077)$ on pelvic floor contractility, with initial median equal 2 and the final equal 4.

In the results of the comparative analysis, before and after the intervention with 21 sessions of Mat Pilates (Figure 2 and Table 3), it can be observed the improvement $(p=0.009)$ of

Table 2. General characteristics of participants. Belém/PA, 2018

\begin{tabular}{ll}
\hline \multicolumn{1}{c}{ Variables } & Prevalence (\%) \\
\hline Final sample size & $12(100.0)$ \\
Marital Status & \\
Single & $5(41.66)$ \\
Married & $6(50.00)$ \\
Divorced & $1(8.33)$ \\
Pregnancies & \\
0 & $3(25.00)$ \\
1 to 2 & $9(75.00)$ \\
more than 2 & $0(0.0)$ \\
Schooling & \\
Complete High School & $3(25.0)$ \\
Technical Degree & $1(8.33)$ \\
Complete College & $3(25.0)$ \\
Incomplete College & $3(25.0)$ \\
Post-Graduation & $2(16.66)$ \\
Urinary Incontinence Symptom & \\
Dripping & $2(16.66)$ \\
Urgency & $1(8.33)$ \\
Post-urination desire & $1(8.33)$ \\
Loss of effort & $4(33.33)$ \\
No symptoms & $7(58.33)$ \\
\hline
\end{tabular}

Table 3. Non-parametric Wilcoxon test in the comparison of FSFI before and after the intervention detailed in median \pm interquartile range. Belém/PA, 2018.

\begin{tabular}{|c|c|c|c|c|c|}
\hline & \multicolumn{2}{|c|}{ Initial FSFI } & \multicolumn{2}{|c|}{ Final FSFI } & \multirow{2}{*}{ Value of $p$} \\
\hline & Median & IQR & Median & IQR & \\
\hline Desire & 3.6 & 0.7 & 3.6 & 0.6 & 0.3980 \\
\hline Excitation & 4.1 & 1.1 & 4.8 & 0.6 & 0.7450 \\
\hline Lubrication & 3.9 & 1.1 & 4.5 & 0.7 & $0.0409 *$ \\
\hline Orgasm & 4.4 & 0.9 & 4.8 & 0.4 & 0.7560 \\
\hline Satisfaction & 4.8 & 1.8 & 5.2 & 0.3 & 0.0858 \\
\hline Pain & 4.6 & 2.0 & 5.4 & 0.5 & $0.0108^{*}$ \\
\hline Total & 25.6 & 5.4 & 28.4 & 1.2 & 0.0099* \\
\hline
\end{tabular}

Note: FSFI= Female Sexual Function Index. ${ }^{*} p<0.05$ = statistically significant difference. sexual function according to the FSFI in the general scope, since the initial median score was 25.6 and the final median score was 28.4, and authors defined that the scores equal to or below 26 would indicate sexual dysfunction ${ }^{(18,20)}$. According to the comparison of the initial and final groups, the initial one presented great variability to the responses whereas the final group showed a homogeneous and higher score.

\section{DISCUSSION}

The main objective of the study was to evaluate the influence of Mat Pilates associated with perineal contraction in female sexual response. It is believed that in order to have better performance and consequently greater satisfaction in the sexual act, it would be important to strengthen the pelvic floor muscle through specific exercises.

The intensity of contraction of the pelvic floor muscle can be obtained through Pilates as much as through a Kegel exercise program, as shown in a study where both lasted 12 weeks and obtained similar results ${ }^{(17)}$.

The Pilates effect associated with the Pelvic Floor Muscle Training (PFMT) was compared to the control group, which

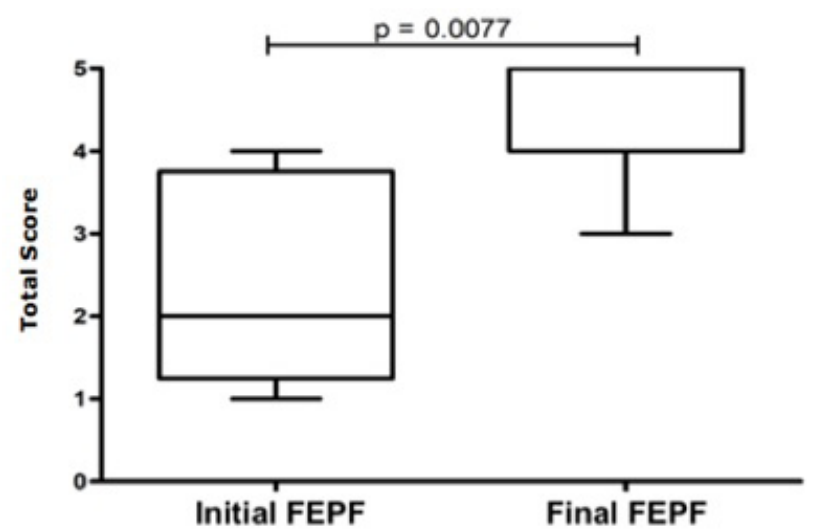

Figure 1. Comparison of the initial and final FEPF (Functional Evaluation of the Pelvic Floor).

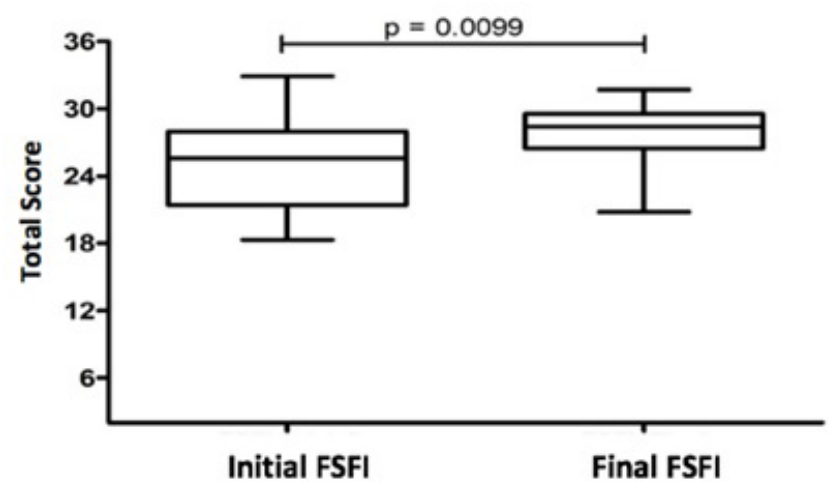

Figure 2. Comparison of the initial and final FSFI (Female Sexual Function Index). 
performed only the Pilates technique without contraction of the PFM. The group of women who practiced Pilates associated with PFMT showed an improvement in the contraction strength of PFM in relation to the control group, which is in agreement with this study, since during the exercise it was requested the contraction of the $\mathrm{PFM}^{(21)}$.

Since 1952, Kegel already believed that the disuse, weakness and hypotonicity of PFM contributed to orgasmic incapacity and that the rehabilitation and strengthening of these had a positive effect on the sexual life of women ${ }^{(22)}$. It is also believed that not only the strengthening, but also the awareness and proprioception of this muscle would promote a greater perception of the perineal region, thus improving the woman's self-image, her receptivity to sexual activity and satisfaction with her performance ${ }^{(23)}$.

In this study, FSFI was chosen because it is an adequate instrument for epidemiological and clinical studies, which is easy to apply and allows the objective evaluation of female sexuality within its multidimensionality and complexity ${ }^{(24,25)}$. In this study, the general domain score of the sexual function of FSFI showed a significant difference, changing the median score from 25.6 to 28.4. It is inferred that this is due to the increase of the contraction capacity of the PFM, associated with Mat Pilates. Analyzing the domains of the questionnaire in a isolate way, were only significant improvements in lubrication $(p=0.04)$ and pain $(p=0.01)$; Also notable is the improvement in the satisfaction $(p=0.08)$, while not statistically significant, it is believed that the sample size $(n=12)$ had interfered since the results are significant in the literature with larger samples ${ }^{(20)}$. In the other domains, there were no statistically significant differences and this result is attributed to the fact that these variables are more related to the psychological component of sexual function than to the physical one, which is supposedly due to increased vascularity in the perineal region, thus improving blood supply in the muscle fascia ${ }^{(26)}$.

Another fact to be highlighted is that a pelvic floor with deficient or inadequate function may be an etiological factor for UI and other PFM-related pathologies. In order to succeed in gaining strength of these muscles, awareness of the perineal region becomes important ${ }^{(27)}$. In a recent systematic review ${ }^{(28)}$, it was confirmed that exercises for the pelvic floor are effective in the treatment of UI, resulting also in the improvement of the quality of life of incontinent women. In the present study, it was observed that only one participant maintained the initial picture regarding UI symptoms, so $91.6 \%$ of the participants who presented UI at the initial evaluation had the total elimination of symptoms after the protocol. The correct contraction of the PMF, especially the anus lifts, has been very effective in the treatment of UI, presenting improvement in the sphincter control, in the recruitment of type I (slow) and II (fast) muscle fibers and in the stimulation of the unconscious functionality ${ }^{(29)}$.
It is also emphasized that is usually not performed the functional evaluation of PFM prior to the beginning of Pilates training. If the training objective included the strengthening of the deep pelvic musculature, such evaluation would be crucial(30).

Evaluation of the pelvic floor is essential for the development of appropriate treatment and monitoring of the results. Currently, there is no evaluation tool that is considered a gold standard; however, the International Continence Committee (ICS) recommends that the evaluation of PFM be performed through vaginal palpation and perineometry, among others ${ }^{(31)}$.

Manual muscle testing is one of the most commonly used ways to assess PFM strength because it is simple to use and does not require expensive equipment ${ }^{(32)}$. Although the evidence does not guarantee that it is reliable when it comes to the inter-evaluators ${ }^{(33)}$, is the most accessible and economical and in this study only one therapist performed the initial and final evaluation to minimize possible measurement errors.

The study presented some limitations mainly due to the small sample size, since the women should have sexual partners and the availability of time for the regular practice of the method. However, we emphasize that the proposed objectives were achieved, and we suggest new researches that seek to verify if the greater time of practice of the method would have a more significant gain in the muscle contraction force, as well as the inclusion of a control group to compare the Pilates Method with other techniques of physical therapy used to strengthen the perineal region.

\section{CONCLUSION}

The Pilates Mat associated with perineal contraction positively influenced the female sexual function and the gain of the contraction capacity of the PFM. However, these results should be checked with caution due to sample size and absence of control group, therefore, it is necessary to carry out controlled studies with a greater number of participants in order to obtain better results.

\section{AUTHORS' CONTRIBUTION}

MECO and FGO presented substantial contributions to the design of the study, as well as performed data collection and application of the method. NSA performed the statistical analysis. EFCN and CNCR contributed to the bibliographical discussion and reviewed the manuscript. All authors agreed after reading the completed manuscript.

\section{CONFLICT OF INTEREST}

The authors declare that there was no conflict of interest.

\section{AUTHORS DETAILS}

2 Universidade da Amazônia (UNAMA), Belém (PA), Brasil

${ }^{3}$ Universidade Estadual do Pará (UEPA), Belém (PA), Brasil

\section{REFERENCES}

1. Moreno A. Fisioterapia em uroginecologia. 2a ed. São Paulo: Manole; 2004. 
2. Rubinstein I. Incontinência Urinária na Mulher. Belo Horizonte: Atheneu; 2001.

3. Gallagher SP, Kryzanowska R. O método de Pilates de Condicionamento Físico. São Paulo: The Pilates Studio ${ }^{\circledR}$ do Brasil, 2000.

4. Dillman E. O pequeno livro de Pilates: guia prática que despensa professores e equipamentos. Rio de Janeiro: Record; 2004.

5. Mattos R, Samano T. Intervenção do Pilates na Reeducação Postural Estudo de Caso. 2005. Disponível em: http://www.fisiometer.com.br/ artigos/Intervencao_do_Pilates_na_Reeducacao_Postural.pdf. Acesso em 28 Mar 2014.

6. Borges J. Princípios básicos do método Pilates. Mó- dulo, 2004.

7. Mattos ML. Princípios do Pilates. Guia de Pilates, ed. on line. 2011;1(1).

8. Souza LM, Pegorare ABGS, Christofoletti G, Barbosa SRM. Influência de um protocolo de exercícios do método Pilates na contratilidade da musculatura do assoalho pélvico de idosas não institucionalizadas. Rev Bras Geriatr Gerontol. Rio de Janeiro. 2017 20(4): 485-493.

9. Queiroz BC, Cagliari MF, Amorim CF, Sacco IC. Muscle activation during four pilates core stability exercises in quadruped position. Arch Phys Med Rehabil. 2010; 91(1): 86-92.

10. Souza LM, Pegorare, AB, Christofoletti G. Influence of a protocol of Pilates exercises on the contractility of the pelvic floor muscles of noninstitutionalized elderly persons. Rev bras geriatr gerontol. 2017;20(4): 484-492.

11. Berek J. S. Novak: tratado de ginecologia. 14ed. Rio de Janeiro: Guanabara Koogan; 2008.

12. Azar M, Noohi S, Radfar S, Radfar MH. Sexual function in women after surgery for pelvic organ prolapse. Int Urogynecol J Pelvic Floor Disfunct. 2008;19(1):53-7.

13. Özel B, White $T$, Urwitz-Lane R, Minaglia $S$. The impact of pelvic organ prolapse on sexual function in women with urinary incontinence. Int Urogynecol J Pelvic Floor Dysfunct. 2006;17(1):14-7.

14. Masters WH, Johnson VE, Kolodny RC. Human sexuality. 2nd ed. Toronto: Little, Brown and Company; 1985

15. Basson, R. Human sex response cycles. J Sex Marital Ther 2001; 27 (1): 33-43.

16. Pasqualotto EB, Pasqualotto FF, Sobreiro BP, Lucon AM. Female sexual dysfunction: the important points to remember. Clinics (Sao Paulo) 2005;60(1):51-60

17. Culligan PJ, Scherer J, Dyer K, Priestley JL, Guingon- White G, Delvecchio $D$, Vangeli M. A randomized clinical trial comparing pelvic floor muscle training to a Pilates exercise program for improving pelvic muscle strength. Int Urogynecol J. 2010;21(4):401-8.

18. Rosen R, Brown C, Heiman J, Leiblum S, Meston CM, Shabsigh R, Ferguson D, D'Agostino R., Jr The Female Sexual Function Index (FSFI): A multidimensional self-report instrument for the assessment of female sexual function. Journal of Sex \& Marital Therapy. 2000;26:191-208.
19. Laycok J, Jerwood D. Pelvic floor muscle assessment: the PERFECT scheme. Physiotherapy. 2001;87(12):631-42.

20. Thiel RRC, Dambros M, Palma PCR, Thiel M, Riccetto CLZ, Ramos MF. Tradução para português, adaptação cultural e validação do Female Sexual Function Index. Rev Bras Ginecol Obstet. 2008;30(10):504-10.

21. Torelli L, Di Bella ZIKJ, Rodrigues CA, Stüpp L, Girão MJBC, Sartori MGF. Effectiveness of adding voluntary pelvic floor muscle contraction to a Pilates exercise program: an assessor-masked randomized controlled trial. Int Urogynecol J. 2016;27(11):1743-1752.

22. Kegel A. Sexual functions of the pubococcygeus muscle. West I Surg Obstet Gynecol. 1952;60(10):521-4.

23. Piassarolli VP, Hardy E, Andrade NF, Ferreira NO, Osis MJD. Treinamento dos músculos do assoalho pélvico nas disfunções sexuais femininas. Rev Bras Ginecol Obstet. 2010; 32(5):234-40.

24. Thiel RRC, Dambros M, Palma PCR, Thiel M, Riccetto CLZ, Ramos MF. Tradução para português, adaptação cultural e validação do Female Sexual Function Index. Rev Bras Ginecol Obstet. 2008;30(10):504-10.

25. Blümel MJE, Binfa EL, Cataldo AP, Carrasco VA, Izaguirre LH, Sarrá CS, et al. Índice de función sexual femenina: un test para evaluar la sexualidad de la mujer. Rev Chil Obstet Ginecol. 2004; 69(2):118-25.

26. Camara CN, Filho MFC, Silva DSG. Relation Between Episiotomy and Osteomioarticular Symptoms. European Scientific Journal. 2016; 12: 353-361.

27. Andrezza El, Serra E. A influência do método pilates no fortalecimento do assoalho pélvico. [periódico na Internet]. [acesso em 20 dez de 2017]. Disponível em: http://portalsaudebrasilcom/artigosspsb/pilates054.pdf.

28. Moroni RM, Magnani PS, Haddad JM, Castro Rde A, Brito LG. Conservative treatment of stress urinary incontinence: a systematic review with meta-analysis of randomized controlled trials. Rev Bras Ginecol Obstet. 2016;38(2):97-111.

29. Grosse D, Sengler J. As Técnicas da Reeducação Perineal. São Paulo: Manole 2002.

30. de Souza LM, Pegorare ABGS, Christofoletti G, Barbosa SRM. Influência de um protocolo de exercícios do método Pilates na contratilidade da musculatura do assoalho pélvico de idosas não institucionalizadas. Rev bras geriatr gerontol. 2017; 20(4):484-492.

31. Staskis D, Kelleher C, Avery K. Initial assessment of urinary and faecal incontinence in adult male and female patients. In: Abrams P, Cardozo L, Wein A, Khoury S, editors. Incontinence: 4th International Consultation on Incontinence. Paris, France: Health Publications; 2009:311-412.

32. Bo K, Sherburn M. Evaluation of female pelvic-floor muscle function and strength. Phys Ther. 2005;85(3):269-82.

33. Sherburn M, Murphy CA, Carroll S, Allen TJ, Galea MP. Investigation of transabdominal real-time ultrasound to visualise the muscles of the pelvic floor. Aust J Physiother. 2005;51(3):167-70. 